\title{
The Dynamics and Variability Model Intercomparison Project (DynVarMIP) for CMIP6: assessing the stratosphere-troposphere system
}

\author{
Edwin P. Gerber ${ }^{1}$ and Elisa Manzini ${ }^{2}$ \\ ${ }^{1}$ Courant Institute of Mathematical Sciences, New York University, 251 Mercer Street, New York, NY 10012, USA \\ ${ }^{2}$ Max-Planck-Institut für Meteorologie, Bundesstraße 53, 20146 Hamburg, Germany
}

Correspondence to: Elisa Manzini (elisa.manzini@mpimet.mpg.de)

Received: 5 April 2016 - Published in Geosci. Model Dev. Discuss.: 9 May 2016

Revised: 10 August 2016 - Accepted: 22 August 2016 - Published: 23 September 2016

\begin{abstract}
Diagnostics of atmospheric momentum and energy transport are needed to investigate the origin of circulation biases in climate models and to understand the atmospheric response to natural and anthropogenic forcing. Model biases in atmospheric dynamics are one of the factors that increase uncertainty in projections of regional climate, precipitation and extreme events. Here we define requirements for diagnosing the atmospheric circulation and variability across temporal scales and for evaluating the transport of mass, momentum and energy by dynamical processes in the context of the Coupled Model Intercomparison Project Phase 6 (CMIP6). These diagnostics target the assessments of both resolved and parameterized dynamical processes in climate models, a novelty for CMIP, and are particularly vital for assessing the impact of the stratosphere on surface climate change.
\end{abstract}

\section{Introduction}

The challenge of addressing the atmospheric circulation response to global warming has recently been highlighted by Shepherd (2014) and Vallis et al. (2015). Understanding circulation changes in the atmosphere, particularly of the midlatitude storm tracks, has been identified by the World Climate Research Programme (WCRP) as one of the grand challenges in climate research. Accurate simulation of the storm track climatology and variability has long proved a challenge for climate prediction models, particularly in the austral hemisphere, where storm track and associated mid- latitude jet stream is generally located too far equatorward and is too persistent (e.g., Kidston and Gerber, 2010; Simpson and Polvani, 2016; Swart and Fyfe, 2012; Wenzel et al., 2016). The storm tracks depend critically on the transport of momentum, heat and chemical constituents throughout the whole atmosphere. Changes in the storm tracks are thus significantly coupled with lower atmosphere processes such as the planetary boundary layer, surface temperature gradients and moisture availability (e.g., Garfinkel et al., 2011; Booth et al., 2013), as well as with processes in the stratosphere, from natural variability on synoptic to intraseasonal timescales (e.g., Baldwin and Dunkerton, 2001) to the response to changes in stratospheric ozone (e.g., Son et al., 2008) and other anthropogenic forcings (e.g., Scaife et al., 2012). Wave coupling between the tropics and high latitudes (e.g., Li et al., 2015) makes regional circulation change a global problem, requiring a careful assessment of dynamical processes across all latitudes.

The Dynamics and Variability Model Intercomparison Project (DynVarMIP) is an endorsed participant in the Coupled Model Intercomparison Project Phase 6 (CMIP6). Rather than proposing new experiments, the DynVarMIP requests additional model output from existing CMIP6 experiments. This additional output is critical for understanding the role of atmospheric dynamics in past, present and future climate. Both resolved processes (e.g., Rossby waves, largescale condensation) and parameterized processes (e.g., gravity waves, subgrid-scale convection and the planetary boundary layer) play important roles in the dynamics and circulation of the atmosphere in models. The DynVarMIP seeks to 
ensure that sufficient diagnostics of key processes in climate models are archived. Without this model output, we will not be able to fully assess the dynamics of mass, momentum and heat transport - essential ingredients in projected circulation changes - nor take advantage of the increasingly accurate representation of the stratosphere in coupled climate models. Our rational is that by simply extending the standard output relative to that in CMIP5 for a selected set of experiments, there is potential for significantly expanding our research capabilities in atmospheric dynamics.

Investigation of the impact of solar variability and volcanic eruptions on climate also relies heavily on atmospheric wave forcing diagnostics, as well as radiative heating rates (particularly in the shortwave). By extending our request to the energy budget and including diagnostics such as diabatic heating from cloud-precipitation processes, research on the links between moist processes and atmospheric dynamics will be enabled as well. The interplay between moist processes and circulation is central to the WCRP Grand Challenge on Clouds, Circulation and Climate Sensitivity (Bony et al., 2015).

The CMIP5 saw a significant upward expansion of models with a more fully resolved stratosphere (e.g., Gerber et al., 2012), and several multi-model studies have investigated the role of the stratosphere in the present climate and in projections of future climate (e.g., Charlton-Perez et al., 2013; Lott et al., 2014; Manzini et al., 2014). The stratosphere impacts tropospheric weather (e.g., though blocking events; Anstey et al., 2013; Shaw et al., 2014), and an improved representation of stratospheric processes can improve synoptic weather forecasts (e.g., Gerber et al., 2012; McTaggartCowan et al., 2011). Coupling between the stratospheric polar vortices and the tropospheric jet streams enhances subseasonal and seasonal predictability in the mid-latitudes (e.g., Baldwin and Dunkerton, 2001; Roff et al., 2011; Sigmond et al., 2013), while in the tropics, the quasi-biennial oscillation affects subseasonal variability and precipitation (e.g., Yoo and Son, 2016) and provides a source of enhanced interannual predictability (e.g., Boer and Hamilton, 2008). The stratosphere has also been implicated in the ENSO teleconnections to the extratropics (e.g., Bell et al., 2009; Cagnazzo and Manzini 2009) and linked with decadal variability in the Atlantic (e.g., Reichler et al., 2012). Finally, the stratosphere plays an important role in climate change (e.g., Scaife et al., 2012), particularly through ozone loss and recovery over Antarctica (e.g., Gerber and Son, 2014; Min and Son, 2013; Thompson et al., 2011; Wilcox and Charlton-Perez, 2013) and through changes in stratospheric water vapor, which impact surface temperatures and climate sensitivity (e.g., Dessler et al., 2013; Solomon et al., 2010). These studies document a growing interest in the role of the middle and upper atmosphere in climate (cf. Kidston et al., 2015). New research in this direction will take full advantage of the DynVarMIP diagnostics.

\section{Objectives and scientific questions}

The DynVarMIP focuses on the interactions between atmospheric variability, dynamics and climate change, with a particular emphasis on the two-way coupling between the troposphere and the stratosphere. To organize the scientific activity within the Model Intercomparison Project (MIP), we have identified the following key questions:

1. How do dynamical processes contribute to persistent model biases in the mean state and variability of the atmosphere, including biases in the position, strength and statistics of the storm tracks, blocking events and the stratospheric polar vortex?

2. What is the role of atmospheric momentum and heat transport in shaping the climate response to anthropogenic forcings (e.g., global warming, ozone depletion), and how do dynamical processes contribute to uncertainty in future climate projections and prediction?

3. How does the stratosphere affect climate variability at intra-seasonal, inter-annual and decadal timescales?

Investigation of these topics will allow the scientific community to address the role of atmospheric dynamics in the key CMIP6 science questions concerning the origin and consequences of systematic model biases, the response of the Earth system to forcing, and how to assess climate change given climate variability (Eyring et al., 2016). In particular, there is a targeted effort to contribute to the storm track theme of the Grand Challenge on Clouds, Circulation and Climate Sensitivity. The DynVarMIP focus on daily fields and diagnostics of the atmospheric flow is also relevant to the Grand Challenge on Climate Extremes, and could also enable contributions to the additional theme on biospheric forcings and feedbacks.

\section{The diagnostics}

The DynVarMIP requests both enhanced archival of standard variables from the CMIP5 and new diagnostics to enable analysis of both resolved and parameterized processes relevant to the dynamics of the atmosphere. The diagnostics are organized around three scientific themes, as detailed below.

\subsection{Atmospheric variability across scales (short name: variability)}

The first request of the DynVarMIP is enhanced archival of standard variables (listed in Table 1) as daily and monthly means. While modeling centers have been archiving increasingly fine horizontal resolution (close to the native model grid), vertical sampling has been limited to standard levels that changed little from CMIP3 to 5.

The need for enhanced vertical resolution is particularly acute in the upper troposphere and lower stratosphere 
Table 1. Variability. Standard (already in CMIP5) variables at daily and monthly mean frequency. New: more vertical levels (plev19) for 3-D daily and the zonal mean geopotential height, 2-D.

\begin{tabular}{lll}
\hline Name & Long name [unit] & Dimension, grid \\
\hline psl & sea level pressure $[\mathrm{Pa}]$ & 2-D, XYT \\
ps & surface air pressure $[\mathrm{Pa}]$ & 2-D, XYT \\
pr & precipitation $\left[\mathrm{kg} \mathrm{m}^{-2} \mathrm{~s}^{-1}\right]$ & 2-D, XYT \\
tas & near-surface air temperature $[\mathrm{K}]$ & $2-\mathrm{D}, \mathrm{XYT}$ \\
uas & eastward near-surface wind $\left[\mathrm{m} \mathrm{s}^{-1}\right]$ & 2-D, XYT \\
vas & northward near-surface wind $\left[\mathrm{m} \mathrm{s}^{-1}\right]$ & 2-D, XYT \\
ta & air temperature $[\mathrm{K}]$ & 3-D, XYZT \\
ua & eastward wind $\left[\mathrm{m} \mathrm{s}^{-1}\right]$ & 3-D, XYZT \\
va & northward wind $\left[\mathrm{m} \mathrm{s}^{-1}\right]$ & 3-D, XYZT \\
wap & omega (i.e., d $p / \mathrm{d} t)\left[\mathrm{Pa} \mathrm{s} \mathrm{s}^{-1}\right]$ & 3-D, XYZT \\
zg & geopotential height $[\mathrm{m}]$ & 3-D, XYZT \\
hus & specific humidity $[1]$ & 3-D, XYZT \\
zmzg & geopotential height $[\mathrm{m}]$ & 2-D, YZT \\
\hline
\end{tabular}

(UTLS), where there are steep vertical gradients in dynamical variables (e.g., temperature and wind) and chemical constituents (e.g., water vapor and ozone) across the tropopause. Without this finer vertical resolution, analyses of the UTLS would be limited by vertical truncation errors, preventing us from taking full advantage of increased horizontal resolution offered in new model integrations.

A number of other MIPs, in particular the HighResMIP (High Resolution Model Intercomparison Project; Haarsma et al., 2016), have also recognized the need for enhanced vertical resolution for daily data. A common proposed request, the "plev19" grid of pressure levels, has consequently been reached (Martin Juckes, personal communication, 2016; see https://earthsystemcog.org/site_media/ projects/wip/CMIP6_pressure_levels.pdf). The pressure levels of the plev19 grid are 1000, 925, 850, 700, 600, 500, 400, $300,250,200,150,100,70,50,30,20,10,5$ and $1 \mathrm{hPa}$.

The diagnostics in Table 1 will allow for evaluation of atmospheric variability across timescales and spacial scales, e.g., the assessment of model biases in blocking events, the tropospheric storm tracks, and the stratospheric polar vortices. Comparison between the pre-industrial control, historical and idealized integrations will allow for evaluation of the response of atmospheric variability to external forcings.

Novel to CMIP6 is also the daily zonal mean geopotential (zmzg, Table 1), tailored to the need of DCPP (Decadal Climate Prediction Project; Boer et al., 2016) to analyze variability on longer timescales and for a large number experiments, while minimizing storage requirements.

\subsection{Atmospheric zonal momentum transport (short name: momentum)}

The second group of diagnostics focuses on the transport and exchange of momentum within the atmosphere and between the atmosphere and surface. These diagnostics are listed in Tables 2, 3 and 4. Within this group, a number of new (to
CMIP) diagnostics and variables are requested. The goal of this set is to properly evaluate the role of both the resolved circulation and the parameterized dynamical processes in momentum transport. As daily timescales must be archived to capture the role of synoptic processes, we focus on the zonal mean circulation, thereby greatly reducing the total output that must be stored permanently. We have also prioritized the new variables, as noted in Tables 2, 3 and 4. Priority 1 variables are essential to the MIP and are required for participation. Priority 2 variables would be very valuable to the MIP, but are not necessary for participation.

The zonal mean quantities (for both daily and monthly means) are requested on the "plev39" grid of pressure levels: $1000,925,850,700,600,500,400,300,250,200,170,150$, $130,115,100,90,80,70,50,30,20,15,10,7,5,3,2,1.5$, $1,0.7,0.5,0.4,0.3,0.2,0.15,0.1,0.07,0.05$ and $0.03 \mathrm{hPa}$. This sampling will allow for detailed exploration of the vertical momentum transport, from the surface to the mesosphere. Subsampling is allowed for models with lower vertical resolution or lower model tops. All three-dimensional (3-D) fields, however, are requested on the plev19 grid.

Models largely resolve the planetary- and synoptic-scale processes that dominate the transport of momentum within the free atmosphere. Quantification of this transport, however, depends critically on vertical and horizontal wave propagation. The transformed Eulerian mean (TEM) framework allows one to efficiently quantify this momentum transport by waves, in addition to estimating the Lagrangian transport of mass by the circulation (e.g., Andrews and McIntyre, 1976, 1978). In the stratosphere, the TEM circulation is thus far more relevant to transport of trace gases (e.g., ozone and water vapor) than the standard Eulerian mean circulation (e.g., Butchart, 2014). We have therefore request diagnostics based on the TEM framework (see Table 2). The details of these calculations are presented in the Appendix, and further insight can be found in the textbooks by Andrews et al. (1987; pages 127-130) and Vallis (2006; chap. 12).

As seen in the Appendix, the TEM diagnostics depend critically on the vertical structure of the circulation, i.e., vertical derivatives of basic atmospheric state and of wave fluxes, and can only be accurately computed from instantaneous fields, as opposed to daily means. Even with the enhanced "plev39" vertical resolution requested above for the standard meteorological variables, we would not be able to reproduce these statistics from the archived output. It is therefore important that these calculations be performed on pressure levels as close to the native grid of the model as possible, before being interpolated to standard levels for archival purposes.

Dynamical processes, which need to be parameterized because they are not resolved on the grid of the model, also play an important role in momentum transport. Gravity waves transport momentum from the surface to the upper troposphere and beyond, but cannot be properly resolved at conventional climate model's resolution. Their wave stresses play a key role in the large-scale circulation of the tropo- 
Table 2. Momentum (atmosphere). Zonal mean variables (2-D, grid: YZT) on the plev39 grid. The zonal mean zonal wind is requested, as it would otherwise be unavailable at this vertical resolution.

\begin{tabular}{|c|c|c|}
\hline Name (priority) & Long name [unit] & Frequency \\
\hline ua (1) & eastward wind $\left[\mathrm{m} \mathrm{s}^{-1}\right]$ & monthly \& daily \\
\hline epfy (1) & northward component of the Eliassen-Palm flux $\left[\mathrm{m}^{3} \mathrm{~s}^{-2}\right]$ & monthly \& daily \\
\hline epfz (1) & upward component of the Eliassen-Palm flux $\left[\mathrm{m}^{3} \mathrm{~s}^{-2}\right]$ & monthly \& daily \\
\hline vtem (1) & Transformed Eulerian mean northward wind $\left[\mathrm{m} \mathrm{s}^{-1}\right]$ & monthly \& daily \\
\hline wtem (1) & Transformed Eulerian mean upward wind $\left[\mathrm{m} \mathrm{s}^{-1}\right]$ & monthly \& daily \\
\hline utendepfd (1) & tendency of eastward wind due to Eliassen-Palm flux divergence $\left[\mathrm{m} \mathrm{s}^{-2}\right]$ & monthly \& daily \\
\hline utendnogw (1) & tendency of eastward wind due to non-orographic gravity waves $\left[\mathrm{m} \mathrm{s}^{-2}\right]$ & daily \\
\hline utendogw (1) & tendency of eastward wind due to orographic gravity waves $\left[\mathrm{m} \mathrm{s}^{-2}\right]$ & daily \\
\hline utendvtem (1) & tendency of eastward wind due to TEM northward wind advection and the Coriolis term $\left[\mathrm{m} \mathrm{s}^{-2}\right]$ & daily \\
\hline utendwtem (1) & tendency of eastward wind due to TEM upward wind advection $\left[\mathrm{m} \mathrm{s}^{-2}\right]$ & daily \\
\hline psitem (2) & Transformed Eulerian mean mass stream-function $\left[\mathrm{kg} \mathrm{s}^{-1}\right]$ & daily \\
\hline mnstrage (2) & mean age of stratospheric air [year] & monthly \\
\hline
\end{tabular}

Table 3. Momentum (atmosphere). Monthly mean variables (3-D, grid: XYZT) on the plev19 grid.

\begin{tabular}{|c|c|c|}
\hline Name (priority) & Long name [unit] & Frequency \\
\hline utendnogw (1) & tendency of eastward wind due to non-orographic gravity waves $\left[\mathrm{m} \mathrm{s}^{-2}\right]$ & monthly \\
\hline utendogw (1) & tendency of eastward wind due to orographic gravity waves $\left[\mathrm{m} \mathrm{s}^{-2}\right]$ & monthly \\
\hline vtendnogw (1) & tendency of northward wind due to non-orographic gravity waves [m s${ }^{-2}$ ] & monthly \\
\hline vtendogw (1) & tendency of northward wind due to orographic gravity waves $\left[\mathrm{m} \mathrm{s}^{-2}\right]$ & monthly \\
\hline
\end{tabular}

sphere (e.g., the storm tracks; Palmer et al., 1986) and are the primary drivers of the stratospheric circulation (e.g., Alexander et al., 2010, and references therein). Atmospheric circulation changes have been shown to be sensitive to the parameterization of gravity waves (e.g., Sigmond and Scinocca, 2010). The availability of tendencies from gravity wave processes (Tables 2 and 3) will enable a systematic evaluation of this driving term of the circulation, so far largely unexplored in a multi-model context.

Additional parameterized processes can impact momentum transport in the free atmosphere, including convective momentum transport, vertical diffusion and sponge layers near the model top (often used to prevent artificial wave reflection). Numerical diffusion can also artificially impact the momentum transport. The impact of these processes will be diagnosed in aggregate, however, as a residual between the total momentum tendency by the resolved flow and gravity waves and the actual change in the resolved flow.

While the TEM circulation approximates the Lagrangian transport of mass, trace gases with sinks and sources in the stratosphere, such as ozone, are also strongly affected by quasi-horizontal mixing along isentropic surfaces (e.g., Plumb, 2002). Breaking Rossby waves rearrange mass along isentropic surfaces: this yields no net movement of mass, but a trace gas with horizontal gradient experiences a net transport. The "age of air" can be used to assess the impact of this mixing, and provides complementary information to the
TEM for the assessment of the stratospheric circulation (e.g., Waugh and Hall, 2002). The age can be quantified by a socalled "clock tracer," a passive tracer with a unit source near the surface; the age is then simply the difference between the concentration at the surface and other points in the atmosphere. This variable is requested at priority 2: not required for participation, but requested from models that have this capability.

Diagnostics to archive the parameterized surface stresses are listed in Table 4. A number of studies have documented that the large-scale circulation and storm track structure are sensitive to the surface drag (e.g., Chen et al., 2007; Garfinkel et al., 2011; Polichtchouk and Shepherd, 2016). These diagnostics will also allow us to connect the CMIP6 with the investigation of weather prediction models by the Working Group on Numerical Experimentation (WGNE) Drag Project (http://collaboration.cmc.ec.gc.ca/science/rpn/ drag_project/). To understand how models arrive at the total surface stress, we also request the component due to turbulent processes, usually parameterized by the planetary boundary layer (PBL) scheme, including those stresses that come from subgrid orographic roughness elements. The role of other processes could then be diagnosed by residual.

Evaluation of the resolved and parameterized processes that effect the circulation is essential to diagnosing and understanding model biases in the mean state and variability of the atmosphere, and for diagnosing the processes driving 
Table 4. Momentum (surface). 2-D variables (Grid: XYT).

\begin{tabular}{lll}
\hline Name (priority) & Long name [unit] & Frequency \\
\hline tauu (1) & surface downward eastward wind stress [Pa] & daily \\
tauv (1) & surface downward northward wind stress [Pa] & daily \\
tauupbl (2) & surface downward eastward wind stress due to boundary layer mixing [Pa] & daily \\
tauvpbl (2) & surface downward northward wind stress due to boundary layer mixing [Pa] & daily \\
\hline
\end{tabular}

Table 5. Heat (atmosphere). 2-D zonal mean variables (2-D grid: YZT) on the plev39 grid. The zonal mean temperature is requested, as it would otherwise be unavailable at this vertical resolution.

\begin{tabular}{|c|c|c|}
\hline Name (priority) & Long name [unit] & Frequency \\
\hline ta $(1)$ & air temperature $[\mathrm{K}]$ & monthly \\
\hline tntmp (1) & tendency of air temperature due to model physics $\left[\mathrm{K} \mathrm{s}^{-1}\right]$ & monthly \\
\hline $\operatorname{tntrl}(1)$ & tendency of air temperature due to longwave heating, all sky $\left[\mathrm{K} \mathrm{s}^{-1}\right]$ & monthly \\
\hline tntrs (1) & tendency of air temperature due to shortwave heating, all sky [ $\left.\mathrm{Ks}^{-1}\right]$ & monthly \\
\hline tntrlcs (2) & tendency of air temperature due to longwave heating, clear sky $\left[\mathrm{K} \mathrm{s}^{-1}\right]$ & monthly \\
\hline $\operatorname{tntrscs}(2)$ & tendency of air temperature due to shortwave heating, clear sky $\left[\mathrm{K} \mathrm{s}^{-1}\right]$ & monthly \\
\hline $\operatorname{tntc}(2)$ & tendency of air temperature due to convection $\left[\mathrm{K} \mathrm{s}^{-1}\right]$ & monthly \\
\hline tntscp (2) & tendency of air temperature due to stratiform clouds and precipitation $\left[\mathrm{K} \mathrm{s}^{-1}\right]$ & monthly \\
\hline tntnogw (2) & tendency of air temperature due to non-orographic gravity wave dissipation $\left[\mathrm{K} \mathrm{s}^{-1}\right]$ & monthly \\
\hline tntogw (2) & tendency of air temperature due to orographic gravity wave dissipation $\left[\mathrm{K} \mathrm{s}^{-1}\right]$ & monthly \\
\hline
\end{tabular}

circulation changes in response to natural and anthropogenic forcing. A careful dynamic analysis of circulation change is a critical step in developing a fundamental understanding of the underlying mechanisms, and hence for improving confidence in future projections. We need to know that models agree not only in the response, but also for the same reasons.

\subsection{The atmospheric heat budget (short name: heat)}

This set of diagnostics allows us to understand the interaction between radiation, moisture and the circulation. As with our momentum diagnostics, we request only zonal mean statistics, to limit the additional storage load (Table 5). We ask for the temperature tendency due to all parameterized physics (e.g., all diabatic processes: radiation, convection, boundary layer, stratiform condensation/evaporation, vertical diffusion). Temperature tendencies due to resolved dynamics and numerical diffusion not associated with parameterized physics are then diagnosed in aggregate, as a residual between the temperature tendency due to all diabatic processes and the actual change in the resolved temperature. To separate the contribution of radiative transfer, we ask for the temperature tendencies due to longwave/shortwave radiative transfer (all sky). If available, the tendencies due to nonorographic/orographic gravity wave dissipation, due to convection (all parameterized types), due to stratiform clouds and precipitation (all type of resolved, large-scale clouds and precipitation) and the tendencies due to clear-sky longwave/shortwave radiative transfer are requested at priority 2 . These would allow for a more careful assessment of dynam- ical, radiative, moisture and cloud processes on the diabatic heat budget (e.g., Wright and Fuegistaler, 2013; Ming et al., 2016).

Separately diagnosing the short- and longwave heating tendencies has proven to be useful for interpreting circulation changes in general (e.g., Fueglistaler et al., 2009; Kim et al., 2013), and is particularly important for understanding the role of solar and volcanic forcings on the circulation. It will allow us to separate the direct impact of changes in solar radiation and aerosol loading from the atmospheric response to these perturbations, and enable analysis to break down feedbacks in Earth system models.

\section{Experiments}

The DynVar diagnostics are requested from the Diagnostic, Evaluation and Characterization of Klima (DECK) experiments and CMIP6 historical simulations (Eyring et al., 2016) and a total of four closely related experiments: one experiment from the Scenario Model Intercomparison Project (ScenarioMIP; O'Neill et al., 2016) and three experiments from the Cloud Feedback Model Intercomparison Project (CFMIP; Webb et al., 2016), as listed in Table 6. To limit the total data storage, the diagnostics are requested for targeted 40-year periods (detailed in Table 6), with the exception of the $1 \% \mathrm{yr}^{-1} \mathrm{CO}_{2}$ increase experiment from the DECK, where only monthly mean diagnostics are requested. As indicated by the third column of Table 6, diagnostics from the DECK and CMIP6 historical simulation are required for 
Table 6. Experiments and integration years for which the DynVarMIP diagnostics are requested. In bold: name of experiment MIP or group.

\begin{tabular}{|c|c|c|}
\hline Experiment & Collection period(s) & Tier \\
\hline \multicolumn{3}{|l|}{ DECK (Eyring et al., 2016) } \\
\hline AMIP & 1979-2014 (ideally for three ensemble members) & 1 \\
\hline Pre-industrial control & $111-150$ years after the branching point & 1 \\
\hline Abrupt quadrupling of $\mathrm{CO}_{2}$ concentration & years $1-40$ and $111-150$ & 1 \\
\hline $1 \% \mathrm{yr}^{-1} \mathrm{CO}_{2}$ concentration increase & years $1-150$ (monthly mean data only) & 1 \\
\hline \multicolumn{3}{|l|}{ CMIP6 historical simulation } \\
\hline Past $\sim 1.5$ centuries & $1961-2000$ & 1 \\
\hline \multicolumn{3}{|l|}{ ScenarioMIP (O'Neill et al., 2016) } \\
\hline SSP5-RCP8.5 & 2061-2100 & 2 \\
\hline \multicolumn{3}{|l|}{ CFMIP (Webb et al., 2016) } \\
\hline amip-p4K & 1979-2014 & 2 \\
\hline amip-future $4 \mathrm{~K}$ & 1979-2014 & 2 \\
\hline amip- $4 \times \mathrm{CO}_{2}$ & 1979-2014 & 2 \\
\hline
\end{tabular}

participation in the DynVarMIP. Diagnostics from the experiments organized by the ScenarioMIP and CFMIP are optional, but highly recommended for modeling centers that participate in these MIPs.

Diagnostics from the pre-industrial control (Atmospheric Model Intercomparison Project - AMIP), and CMIP6 historical simulations are most relevant to our first scientific objective, to understand biases in atmospheric circulation and variability. In particular, the circulation in the latter two experiments can be directly compared against atmospheric reanalyses of the observed atmosphere. Comparison against integrations under strong anthropogenic influence (the last 40 years of the abrupt quadrupling of $\mathrm{CO}_{2}$ experiment and years 2061-2100 from the SSP5-RCP8.5 experiment) will help reveal how biases in the historical climatology relate to biases in the future climate projections (e.g., Wenzel et al., 2016).

Our second objective is to understand the circulation response to anthropogenic forcing, and will be served by analysis of the equilibrated response of the atmosphere to $4 \times \mathrm{CO}_{2}$ and the late 21st century circulation in the SSP5-RCP8.5 experiment. Wu et al. (2013), Grise and Polvani (2014a) and Shaw and Voigt (2015), however, have shown how the initial response of the atmosphere to an abrupt quadrupling of $\mathrm{CO}_{2}$ reveals a great deal about the dynamical mechanism(s) and their associated timescales; hence, our request for the first 40 years of this integration. A number of studies from the CMIP5 have also demonstrated the utility of AMIP climate change experiments, the amip-p $4 K$, amip-future $4 K$ and amip- $4 \times \mathrm{CO}_{2}$ organized by the CFMIP, in isolating the mechanisms for circulation changes (e.g., Grise and Polvani, 2014b; He and Soden, 2015; Shaw and Voigt, 2015). We have therefore requested diagnostics from these simulations from modeling centers, which are also participating in the CFMIP.
Lastly, diagnostics are requested from the full 150-year record from the $1 \% \mathrm{yr}^{-1} \mathrm{CO}_{2}$ increase experiment, specifically to determine the time of emergence in circulation changes. To limit the cost of archiving this data, only monthly mean fields are requested.

Our final objective, to understand the role of stratosphere in surface climate and variability, will be served by a number of these simulations. The pre-industrial control and final 40 years of the abrupt quadrupling of $\mathrm{CO}_{2}$ integrations, however, will be particularly ideal for understanding the role of stratosphere in natural, unforced variability in past and future climates, respectively.

The DynVar diagnostics (or relevant subsets thereof) have been coordinated with diagnostic requests of other CMIP6 endorsed MIPs. The TEM and stratospheric circulation diagnostics are highly relevant to integrations with ozone depleting substances in the Aerosols and Chemistry MIP (AeroChemMIP; Collins et al., 2016) and to the short-term response of the atmosphere to volcanic forcing, as detailed in the Volcanic Forcings Model Intercomparison Project (VolMIP; Zanchettin et al., 2016). The zonal mean long- and shortwave heating rates have been requested for integrations focused on solar variability in the Detection and Attribution MIP (DAMIP; Gillett et al., 2016). Zonal mean geopotential height has been requested as part of the Decadal Climate Prediction Project (DCPP; Boer et al., 2016). Finally, the enhanced archival of daily data and gravity wave drag diagnostics were coordinated with the HighResMIP (Haarsma et al., 2016).

\section{Analysis plan}

The DynVarMIP has been organized in response to our experience in coordinating community-based, collaborative analysis of coupled climate models from the CMIP5 through 
the stratosphere-troposphere processes and their role in climate (SPARC) DynVar activity (e.g., Gerber et al., 2012; Charlton-Perez et al., 2013; Manzini et al., 2014). An analysis plan for the MIP was formulated at an open workshop held in Helsinki, Finland, in June 2016. The workshop was attended by approximately 70 scientists from around the world, with broad representation from the modeling and research communities, and held jointly with a subset of the SPARC Reanalysis Intercomparison Project (S-RIP). Three groups were organized to coordinate analysis of the DynVarMIP research objectives.

The first group focused on model biases, and will begin with a systematic analysis of the TEM circulation and momentum budget in CMIP6 models. A community paper (or potentially a series of papers) is being organized to follow up more systematically on Hardiman et al. (2013), which compared the residual circulation across a subset of CMIP5 models where the relevant diagnostics could be collected on an ad hoc basis. The first paper will focus the momentum and heat balances of the historical climate, where it can be directly compared with observations. Several of the group members are involved in the S-RIP chapter on the Brewer-Dobson circulation, bringing expertise on potential limitations in our understanding of the momentum and heat budgets in reanalysis.

Two approaches were suggested for the DynVarMIP objective on the response of the circulation to anthropogenic forcing. The first is to extend the systematic, community organized analysis of the heat and momentum budgets to climate change scenarios, with an emphasis on links between the models' ability to capture the past climate with their projections of future circulation changes. The second is to continue informal coordination of research on the underlying mechanisms. Based on past experience, we have found that research on a mechanistic understanding of the atmosphere is often best organized organically, rather than from a topdown approach. The potential for a review paper on model hierarchies, which help link basic research to comprehensive climate models, was raised, and will be explored in greater detail at the upcoming WCRP workshop on model hierarchies in November 2016.

A third group focused on the natural variability of the atmosphere, with a particular emphasis on initial condition predictability (i.e., predictability of the first kind; Lorenz, 1975) in CMIP6 models across a range of timescales, from synoptic to decadal. Charlton-Perez et al. (2013) concluded that a better representation of the stratosphere in climate models strongly impacts the variability of the stratosphere, and it is an open question as to the extent which this improves the representation of natural variability in the troposphere. Subseasonal variability was identified as an important, but less explored area in climate research. It is also a timescale for which the stratosphere is particularly relevant, and a review paper was proposed to motivate more systematic analysis of variability on this timescale in CMIP6 models.
To ensure continued participation and collaboration with the modeling centers, representatives from the modeling centers have been invited to participate in the scientific analysis and papers. A future workshop (tentatively set for 2019 at which time CMIP6 data are expected to be available) will be arranged to ensure completion of the analysis.

\section{Conclusions and outlook}

The goal of the DynVarMIP is to evaluate and understand the role of dynamics in climate model biases and in the response of the climate system to external forcing. This goal is motivated by the fact that biases in the atmospheric circulation greatly limit our ability to project regional climate change, and compromise our ability to project changes in extreme events.

Rather than proposing new experiments, DynVarMIP has organized a targeted list of variables and diagnostics to characterize the role of both resolved and parameterized dynamical processes in the large-scale circulation of climate models. The DynVarMIP emerged from the needs of an international community of scientists with strong connections to the modeling centers, continuing a collaborative effort with a long history (from the SPARC/GRIPS workshops in the mid1990s; Pawson et al., 2000). Given this participation, we expect that the new diagnostics can be efficiently produced and will be fully utilized.

We are coordinating our efforts with several other CMIP6 activities. Transport plays a key role in the AeroChemMIP experiments with ozone depleting substances, making the TEM diagnostics particularly relevant. The shortterm VolMIP experiments and DAMIP experiments focused on solar variability in large part depend on stratospheretroposphere coupling, where the momentum and heat budget diagnostics are directly relevant. Lastly, gravity wave effects and high-frequency eddy processes are foci of the HighResMIP. The availability of dynamically oriented diagnostics within the DECK and the CMIP6 historical experiment will provide the benchmark for these MIPs and others as well.

\section{Data availability}

The model output generated by the DynVarMIP diagnostic request will be distributed through the Earth System Grid Federation (ESGF) with digital object identifiers (DOIs) assigned. As in CMIP5, it will be freely accessible through data portals after registration. In order to document CMIP6's scientific impact and enable ongoing support of CMIP, users are obligated to acknowledge CMIP6, the participating modeling groups and the ESGF centers. See Eyring et al. (2016) for further details. 


\section{Appendix A: TEM recipe}

This technical appendix outlines and gives recommendation on how to calculate the TEM diagnostics for the momentum budget DynVarMIP output request (Table A1, subset of Table 2, Sect. 3.2). For the calculation of the TEM diagnostics we follow Andrews et al. (1983, 1987). The diagnostics must be calculated on pressure surfaces, ideally spaced very close to, if not identical to, the native levels of the dynamical core of the atmospheric model. For non-hydrostatic dynamical models in geometric- $z$ coordinate, prior to the diagnostic calculation it is necessary to transform the input variables to pressure coordinates, as demonstrated by Hardiman et al. (2010).

Given that the TEM diagnostics are usually displayed in a log-pressure vertical coordinate system (e.g., Butchart, 2014), we thereafter detail how to transform the results to a standard log-pressure vertical coordinate and so obtain the formulation of Andrews et al. (1987), which is the one of our data request, but for a re-scaling of the Eliassen-Palm flux and the TEM mass stream function.

\section{A1 Coordinates, averages and frequency}

Fields of interest must be interpolated to pressure levels prior to taking zonal and temporal averages. Ideally, the pressure levels should be as close as possible to the average position of the model levels, to minimize the impact of interpolation. The TEM diagnostics are particularly sensitive to vertical derivatives, and it is important to keep the full vertical resolution of the atmospheric model until interpolating the final results to the standardized output levels for archival.

Flux quantities with multiplying factors (e.g., heat flux $v^{\prime} \theta^{\prime}$ ) composed of anomalies from the zonal mean (e.g., $v^{\prime}=$ $v-\bar{v}$, where the overbar indicates a zonal mean) should be computed from instantaneous high-frequency data (6-hourly or higher frequency) and their products then computed before averaging to daily or monthly mean.

Time averages are calculated by averaging over the day or month periods, either from instantaneous model output at $6 \mathrm{~h}$ or higher frequency or (where available) directly computed over all time steps. Similarly, zonal averages are calculated averaging over all available longitudes. Zonal averages in the lower atmosphere can pose a problem when pressure surfaces intersect the surface. We recommend that modeling centers either (1) extrapolate the required variables below the surface before computing the diagnostics (see, for example, Trenberth et al., 1993) or (2) take a representative average over all longitudes that are still above the surface. With the second option, a zonal average should be marked missing only if the pressure level is below the surface at more than half of all longitudes. Likewise, a time average should be take over time steps for which the data are available, and only marked missing if more than half the data are missing.

\section{A2 Input}

The input to the calculation of the TEM diagnostics, is given in Table A2. In the following to simplify the writing of the TEM recipe, for the input we use

$T$ for air temperature, variable ta in the Climate Model Output Rewriter (CMOR);

$u$ for eastward wind velocity, ua variable in CMOR;

$v$ for northward wind velocity, va variable in CMOR;

$\omega$ for omega, wap variable in CMOR (vertical component of velocity in pressure coordinates, positive down);

$p$ for pressure $(\mathrm{Pa})$, plev dimension in CMOR;

$\phi$ for latitude (radiant), derived from the latitude (degrees north) dimension in CMOR.

Recommended constants for the calculation of the TEM diagnostics:

$$
\begin{aligned}
& p_{0}=101325 \mathrm{~Pa} \text {, surface pressure; } \\
& R=287.058 \mathrm{~J} \mathrm{~K}^{-1} \mathrm{~kg}^{-1} \text {, gas constant for dry air; } \\
& C_{p}=1004.64 \mathrm{~J} \mathrm{~K}^{-1} \mathrm{~kg}^{-1}, \text { specific heat for dry air, at } \\
& \text { constant pressure; } \\
& \begin{array}{l}
g_{0}=9.80665 \mathrm{~m} \mathrm{~s}^{-1}, \text { global average of gravity at mean } \\
\text { sea level; }
\end{array} \\
& a=6.37123 \times 10^{6} \mathrm{~m}, \text { Earth's radius; } \\
& \Omega=7.29212 \times 10^{-5} \mathrm{~s}^{-1}, \text { Earth's rotation rate; } \\
& f=2 \Omega \sin \phi, \text { Coriolis parameter; } \\
& \pi=3.14159, \text { pi, mathematical constant. }
\end{aligned}
$$

The following derivation of the TEM diagnostics makes use of the potential temperature, defined by

$\theta=T\left(p_{0} / p\right)^{k}$,

where $k=R / C_{p}$ is the ratio of the gas constant, $R$, to the specific heat, $C_{p}$, for dry air.

\section{A3 TEM Diagnostics}

First, the input variables are zonally averaged and the anomalies from the respective zonally averaged quantities are calculated. The zonally averaged quantities are denoted: $\bar{\theta}, \bar{u}, \bar{v}$ and $\bar{\omega}$. The anomalies: $\theta^{\prime}, u^{\prime}, v^{\prime}$ and $\omega^{\prime}$.

Thereafter, fluxes and their zonal averages are calculated, for $\overline{u^{\prime} v^{\prime}}$, the northward flux of eastward momentum, $\overline{u^{\prime} \omega^{\prime}}$, the upward flux of eastward momentum and $\overline{v^{\prime} \theta^{\prime}}$, the northward flux of potential temperature. 
Table A1. Momentum budget variable list (2-D monthly / daily zonal means, YZT).

\begin{tabular}{ll}
\hline Name & Long name [unit] \\
\hline epfy & northward component of the Eliassen-Palm flux $\left[\mathrm{m}^{3} \mathrm{~s}^{-2}\right]$ \\
epfz & upward component of the Eliassen-Palm flux $\left[\mathrm{m}^{3} \mathrm{~s}^{-2}\right]$ \\
vtem & Transformed Eulerian mean northward wind $\left[\mathrm{m} \mathrm{s}^{-1}\right]$ \\
wtem & Transformed Eulerian mean upward wind $\left[\mathrm{m} \mathrm{s}^{-1}\right]$ \\
psitem & Transformed Eulerian mean mass stream function $\left[\mathrm{kg} \mathrm{s}^{-1}\right]$ \\
utendepfd & tendency of eastward wind due to Eliassen-Palm flux divergence $\left[\mathrm{m} \mathrm{s}^{-2}\right]$ \\
utendvtem & tendency of eastward wind due to TEM northward wind advection and the Coriolis term [m s $\left.{ }^{-2}\right]$ \\
utendwtem & tendency of eastward wind due to TEM upward wind advection $\left[\mathrm{m} \mathrm{s}^{-2}\right]$ \\
\hline
\end{tabular}

Table A2. Input for a TEM diagnostic program (CMOR convention).

\begin{tabular}{llll}
\hline Name & Long name [unit] & Dimension & Frequency \\
\hline ta & Air temperature $[\mathrm{K}]$ & $3-\mathrm{D}$ & $\mathrm{HF}=6 \mathrm{~h}$ or higher frequency \\
ua & Eastward Wind $\left[\mathrm{m} \mathrm{s}^{-1}\right]$ & $3-\mathrm{D}$ & $\mathrm{HF}=6 \mathrm{~h}$ or higher frequency \\
va & Northward Wind $\left[\mathrm{m} \mathrm{s}^{-1}\right]$ & $3-\mathrm{D}$ & $\mathrm{HF}=6 \mathrm{~h}$ or higher frequency \\
wap & omega $(=\mathrm{d} p / \mathrm{d} t)\left[\mathrm{Pa} \mathrm{s}^{-1}\right]$ & $3-\mathrm{D}$ & $\mathrm{HF}=6 \mathrm{~h}$ or higher frequency \\
\hline
\end{tabular}

Now we can proceed to calculate the Eliassen-Palm flux, $\mathbf{F}$, its divergence, $\boldsymbol{\nabla} \cdot \mathbf{F}$, the transformed Eulerian mean velocities, $\bar{v}^{*}$ and $\bar{\omega}^{*}$, the mass stream function, $\Psi$.

The Eliassen-Palm flux is a 2-D vector, $\mathbf{F}=\left\{F_{(\phi)} F_{(p)}\right\}$, with northward and vertical components respectively defined by

$$
\begin{aligned}
& F_{(\phi)}=a \cos \phi\left\{\frac{\partial \bar{u}}{\partial p} \psi-\overline{u^{\prime} v^{\prime}}\right\}, \\
& F_{(p)}=a \cos \phi\left\{\left[f-\frac{\partial \bar{u} \cos \phi}{a \cos \phi \partial \phi}\right] \psi-\overline{u^{\prime} \omega^{\prime}}\right\},
\end{aligned}
$$

where

$\psi=\overline{v^{\prime} \theta^{\prime}} / \frac{\partial \bar{\theta}}{\partial p}$

is the eddy stream function.

The Eliassen-Palm divergence, $\nabla \cdot \mathbf{F}$, is defined by

$\nabla \cdot \mathbf{F}=\frac{\partial F_{(\phi)} \cos \phi}{a \cos \phi \partial \phi}+\frac{\partial F_{(p)}}{\partial p}$.

The transformed Eulerian mean northward and vertical velocities are respectively defined by

$\bar{v}^{*}=\bar{v}-\frac{\partial \psi}{\partial p}$,

$\bar{\omega}^{*}=\bar{\omega}+\frac{\partial \psi \cos \phi}{a \cos \phi \partial \phi}$.

The mass stream function (in units of $\mathrm{kg} \mathrm{s}^{-1}$ ), at level $p$ is defined by

$\Psi(p)=\frac{2 \pi a \cos \phi}{g_{0}}\left[\int_{p}^{0} \bar{v} \mathrm{~d} p-\psi\right]$, with upper boundary condition (at $p=0$ ): $\psi=0$ and $\Psi=0$.

The eastward wind tendency, $\left.\frac{\partial \bar{u}}{\partial t}\right|_{\operatorname{adv}\left(\bar{v}^{*}\right)}$, due to the TEM northward wind advection and Coriolis term is given by

$\left.\frac{\partial \bar{u}}{\partial t}\right|_{\operatorname{adv}\left(\bar{v}^{*}\right)}=\bar{v}^{*}\left[f-\frac{\partial \bar{u} \cos \phi}{a \cos \phi \partial \phi}\right]$.

The eastward wind tendency, $\left.\frac{\partial \bar{u}}{\partial t}\right|_{\operatorname{adv}\left(\bar{\omega}^{*}\right)}$, due to the TEM vertical wind advection is given by

$\left.\frac{\partial \bar{u}}{\partial t}\right|_{\operatorname{adv}\left(\bar{\omega}^{*}\right)}=-\bar{\omega}^{*} \frac{\partial \bar{u}}{\partial p}$.

\section{A4 Transformation to log-pressure coordinate}

We define a log-pressure coordinate (Andrews et al., 1987) by

$z=-H \ln \left(p / p_{0}\right)$,
$p=p_{0} e^{-z / H}$,

where $H=R T_{\mathrm{s}} / g_{0}$ is a mean scale height of the atmosphere. We recommend to use $H=7 \mathrm{~km}$, corresponding to $T_{\mathrm{s}} \approx 240 \mathrm{~K}$, a constant reference air temperature.

The Eliassen-Palm flux in log-pressure coordinate, $\hat{F}=$ $\left\{\hat{F}_{(\phi)} \hat{F}_{(z)}\right\}$, is then obtained from the pressure coordinate by

$$
\begin{aligned}
& \hat{F}_{(\phi)}=\frac{p}{p_{0}} F_{(\phi)}, \\
& \hat{F}_{(z)}=-\frac{H}{p_{0}} F_{(p)} .
\end{aligned}
$$

The Andrews et al. (1987) formulation is then multiplied by the constant reference density $\rho_{\mathrm{S}}=p_{0} / R T_{\mathrm{s}}$, which is 
used in the definition of the background density profile $\rho_{0}=$ $\rho_{\mathrm{s}} e^{-z / H}$ in the log-pressure coordinate system. Here, this scaling is not applied in order to maintain the unit of the Eliassen-Palm flux in $\mathrm{m}^{3} \mathrm{~s}^{-2}$.

The Eliassen-Palm divergence in log-pressure coordinate is

$\nabla_{(z)} \cdot \hat{\mathbf{F}}=\frac{\partial \hat{F}_{(\phi)} \cos \phi}{a \cos \phi \partial \phi}+\frac{\partial \hat{F}_{(z)}}{\partial z}=\frac{p}{p_{0}} \nabla \cdot \mathbf{F}$.

The transformed Eulerian mean upward wind velocity is

$\bar{w}^{*}=-\frac{H}{p} \bar{\omega}^{*}$.

\section{A5 Output}

In summary, the TEM recipe output maps to the CMOR variables listed in Table A1 as follows:

$\hat{F}_{(\phi)} \rightarrow$ epfy, northward component of the EliassenPalm flux, Eq. (13);

$\hat{F}_{(z)} \rightarrow$ epfz, upward component of the Eliassen-Palm flux, Eq. (14); $\bar{v}^{*} \rightarrow$ vtem, transformed Eulerian mean northward wind, Eq. (6);

$\bar{w}^{*} \rightarrow$ wtem, transformed Eulerian mean upward wind, Eq. (16);

$\hat{\Psi} \rightarrow$ psitem, transformed Eulerian mean mass stream function, Eq. (8);

$\nabla_{(z)} \cdot \hat{F} \rightarrow$ utendepfd, tendency of eastward wind due to Eliassen-Palm flux divergence, Eq. (15);

$\left.\frac{\partial \bar{u}}{\partial t}\right|_{\operatorname{adv}\left(\bar{v}^{*}\right)} \rightarrow$ utendvtem, tendency of eastward wind due to TEM northward wind advection and the Coriolis term, Eq. (9);

$\left.\frac{\partial \bar{u}}{\partial t}\right|_{\operatorname{adv}\left(\bar{\omega}^{*}\right)} \rightarrow$ utendwtem, tendency of eastward wind due to TEM upward wind advection, Eq. (10). 
Acknowledgements. The DynVarMIP developed from a wide community discussion. We are grateful for the input of many colleagues. In particular we would like to thank Julio Bachmeister, Thomas Birner, Andrew Charlton-Perez, Steven Hardiman, Martin Juckes, Alexey Karpechko, Chihirio Kodama, Hauke Schmidt, Tiffany Shaw, Ayrton Zadra and many others for discussion and their comments on previous versions of the manuscript or parts of it. We gratefully acknowledge the insights and comments from the reviewers and the interactive commenters. Their remarks, together with the lively discussions and presentations at the DynVar workshop in Helsinki, have significantly improved the manuscript. We extend our thanks to Alexey Karpechko for his smooth running of the workshop in Helsinki. EPG acknowledges support from the US National Science Foundation under grant AGS-1546585.

Edited by: O. Morgenstern

Reviewed by: two anonymous referees

\section{References}

Alexander, M. J., Geller, M., McLandress, C., Polavarapu, S., Preusse, P., Sassi, F., Sato, K., Eckermann, S., Ern, M., Hertzog, A., Kawatani, Y., Pulido, M., Shaw, T. A., Sigmond, M., Vincent R., and Watanabe, S.: Recent developments in gravity-wave effects in climate models and the global distribution of gravitywave momentum flux from observations and models, Q. J. Roy. Meteor. Soc. 136, 1103-1124, doi:10.1002/qj.637, 2010.

Andrews, D. G. and McIntyre, M. E.: Planetary waves in horizontal and vertical shear: The generalized Eliassen-Palm relation and the mean zonal acceleration, J. Atmos. Sci., 33, 2031-2048, 1976.

Andrews, D. G. and McIntyre, M. E.: Generalized Eliassen-Palm and Charney-Drazin theorems for waves on axisymmetric mean flows in compressible atmospheres, J. Atmos. Sci., 35, 175-185, 1978.

Andrews, D. G., Mahlman, J. D., and Sinclair, R. W.: Eliassen-Palm Diagnostics of wave-mean flow interaction in the GFDL SKYHI general circulation model, J. Atmos. Sci., 40, 2768-2784, 1983.

Andrews, D. G., Holton, J. R., and Leovy, C. B.: Middle Atmospheric Dynamics, 489 pp., Academic Press, San Diego, California, 1987.

Anstey, J. A., Davini, P., Gray, L. J., Woollings, T. J., Butchart, N., Cagnazzo, C., Christiansen, B., Hardiman, S. C., Osprey, S. M., and Shuting, Y.: Multi-model analysis of Northern Hemisphere winter blocking: Model biases and the role of resolution, J. Geophys. Res.-Atmos., 118, 3956-3971, doi:10.1002/jgrd.50231, 2013.

Baldwin, M. P. and Dunkerton, T. J.: Stratospheric harbingers of anomalous weather regimes, Science, 294, 581-584, 2001.

Bell, C. J., Gray, L. J., Charlton-Perez, A. J., Joshi, M. M., and Scaife, A. A.: Stratospheric communication of El Niño teleconnections to European winter, J. Climate, 22, 4083-4096, 2009.

Boer, G. J. and Hamilton, K.: QBO influence on extratropical predictive skill, Clim. Dynam., 31, 987-1000, 2008.

Boer, G. J., Smith, D. M., Cassou, C., Doblas-Reyes, F., Danabasoglu, G., Kirtman, B., Kushnir, Y., Kimoto, M., Meehl, G. A., Msadek, R., Mueller, W. A., Taylor, K., and Zwiers, F.: The
Decadal Climate Prediction Project, Geosci. Model Dev. Discuss., doi:10.5194/gmd-2016-78, in review, 2016.

Bony, S., Stevens, B., Frierson, D. M. W., Jakob, C., Kageyama, M., Pincus, R., Shepherd, T. G., Sherwood, S. C., Siebesma, A. P., Sobel, A. H., Watanabe, M., and Webb, M. J.: Clouds, circulation and climate sensitivity, Nat. Geosci., 8, 261-268, doi:10.1038/NGEO2398, 2015.

Booth, J. F., Wang, S., and Polvani, L.: Midlatitude storms in a moister world: lessons from idealized baroclinic life cycle experiments, Clim. Dynam., 41, 787-802, doi:10.1007/s00382-0121472-3, 2013.

Butchart, N.: The Brewer-Dobson circulation, Rev. Geophys., 52, 157-184, doi:10.1002/2013RG000448, 2014.

Cagnazzo, C. and Manzini, E.: Impact of the stratosphere on the winter tropospheric teleconnections between ENSO and the North Atlantic and European Region, J. Climate, 22, 1223-1238, doi:10.1175/2008JCLI2549.1, 2009

Charlton-Perez, A. J., Baldwin, M., Birner, T., Black, R. X., Butler, A. H., Calvo, N., Davis, N. A., Gerber, E. P., Gillett, N., Hardiman, S., Kim, J., Krueger, K., Lee, Y.-Y., Manzini, E., McDaniel, B. A., Polvani, L., Reichler, T., Shaw, T. A., Sigmond, M., Son, S.-W., Tohey, M., Wilcox, L., Yoden, S., Christiansen, B., Lott, F., Shindell, D., Yukimoto, S., and Watanabe, S.: On the lack of stratospheric dynamical variability in low-top versions of the CMIP5 models, J. Geophys. Res.-Atmos., 118, 2494-2505, doi:10.1002/jgrd.50125, 2013.

Chen, G. I., Held, I. M., and Robinson, W. A.: Sensitivity of the Latitude of Surface Westerlies to Surface Friction, J. Atmos. Sci., 64, 2899-2915, doi:10.1175/JAS3995.1, 2007.

Collins, W. J., Lamarque, J.-F., Schulz, M., Boucher, O., Eyring, V., Hegglin, M. I., Maycock, A., Myhre, G., Prather, M., Shindell, D., and Smith, S. J.: AerChemMIP: Quantifying the effects of chemistry and aerosols in CMIP6, Geosci. Model Dev. Discuss., doi:10.5194/gmd-2016-139, in review, 2016.

Dessler, A. E., Schoeberl, M. R., Wang, T., Davis, S. M., and Rosenlof, K. H.: Stratospheric Water Vapor Feedback, P. Natl. Acad. Sci. USA, 110, 18087-18091, doi:10.1073/pnas.1310344110, 2013.

Eyring, V., Bony, S., Meehl, G. A., Senior, C. A., Stevens, B., Stouffer, R. J., and Taylor, K. E.: Overview of the Coupled Model Intercomparison Project Phase 6 (CMIP6) experimental design and organization, Geosci. Model Dev., 9, 1937-1958, doi:10.5194/gmd-9-1937-2016, 2016.

Fueglistaler, S., Legras, B., Beljaars, A., Morcrette, J.-J., Simmons, A., Tompkins, A. M., and Uppala, S.: The diabatic heat budget of the upper troposphere and lower/mid stratosphere in ECMWF reanalyses, Q. J. Roy. Meteor. Soc., 135, 21-37, 2009.

Garfinkel, C. I., Molod, A. M., Oman, L. D., and Song, I.-S.: Improvement of the GEOS-5 AGCM upon updating the Air-Sea Roughness Parameterization, Geophys. Res. Lett., 38, L18702, doi:10.1029/2011GL048802, 2011.

Gillett, N. P., Shiogama, H., Funke, B., Hegerl, G., Knutti, R., Matthes, K., Santer, B. D., Stone, D., and Tebaldi, C.: Detection and Attribution Model Intercomparison Project (DAMIP), Geosci. Model Dev. Discuss., doi:10.5194/gmd-2016-74, in review, 2016.

Gerber, E. P. and Son, S.-W.: Quantifying the Summertime Response of the Austral Jet Stream and Hadley Cell to Strato- 
spheric Ozone and Greenhouse Gases, J. Climate, 27, 55385559, doi:10.1175/JCLI-D-13-00539.1, 2014.

Gerber, E. P., Butler, A., Calvo, N., Charlton-Perez, A., Giorgetta, M., Manzini, E., Perlwitz, J., Polvani, L. M., Sassi, F., Scaife, A. A., Shaw, T. A., Son, S.-W., and Watanabe, S.: Assessing and Understanding the Impact of Stratospheric Dynamics and Variability on the Earth System, B. Am. Meteorol. Soc., 93, 845-859, doi:10.1175/BAMS-D-11-00145.1, 2012.

Grise, K. M. and Polvani, L. M.: Southern Hemisphere clouddynamics biases in CMIP5 models and their implications for climate projections, J. Climate, 27, 6074-6092, 2014a.

Grise, K. M. and Polvani, L. M.: The response of mid-latitude jets to increased $\mathrm{CO}_{2}$ : Distinguishing the roles of sea surface temperature and direct radiative forcing, Geophys. Res. Lett., 41, 68636871, 2014b.

Haarsma, R. J., Roberts, M., Vidale, P. L., Senior, C. A., Bellucci, A., Bao, Q., Chang, P., Corti, S., Fuckar, N. S., Guemas, V., von Hardenberg, J., Hazeleger, W., Kodama, C., Koenigk, T., Leung, L. R., Lu, J., Luo, J.-J., Mao, J., Mizielinski, M. S., Mizuta, R., Nobre, P., Satoh, M., Scoccimarro, E., Semmler, T., Small, J., and von Storch, J.-S.: High Resolution Model Intercomparison Project (HighResMIP), Geosci. Model Dev. Discuss., doi:10.5194/gmd-2016-66, in review, 2016.

Hardiman, S. C., Andrews, D. G., White, A. A., Butchart, N., and Edmond, I.: Using Different Formulations of the Transformed Eulerian Mean Equations and Eliassen-Palm Diagnostics in General Circulation Models, J. Atmos. Sci., 67, 1983-1995, doi:10.1175/2010JAS3355.1, 2010.

Hardiman, S. C., Butchart, N., and Calvo, N.: The morphology of the Brewer-Dobson circulation and its response to climate change in CMIP5 simulations, Q. J. Roy. Meteor. Soc., doi:10.1002/qj.2258, 2013.

He, J. and Soden, B. J.: Anthropogenic weakening of the tropical circulation: The relative roles of direct $\mathrm{CO}_{2}$ forcing and sea surface temperature change, J. Climate, 28, 8728-8742, doi:10.1175/JCLI-D-15-0205.1, 2015.

Kidston, J. and Gerber, E. P.: Intermodel Variability of the Poleward Shift of the Austral Jet Stream in the CMIP3 Integrations Linked to Biases in 20th Century Climatology, Geophys. Res. Lett., 37, L09708, doi:10.1029/2010GL042873, 2010.

Kidston, J., Scaife, A. A., Hardiman, S. C., Mitchell, D. M., Butchart, N., Baldwin, M. P., and Gray, L. J.: Stratospheric influence on tropospheric jet streams, storm tracks and surface weather, Nat. Geosci., 8, 433-440, doi:10.1038/ngeo2424, 2015.

Kim, J., Grise, K. M., Son, S.-W.: Thermal characteristics of the cold-point tropopause region in CMIP5 models, J. Geophys. Res.-Atmos., 118, 8827-8841, 2013.

Li, X., Gerber, E. P., Holland, D. H., and Yoo, C.: A Rossby Wave Bridge from the Tropical Atlantic to West Antarctica, J. Climate, 28, 2256-2273, doi:10.1175/JCLI-D-14-00450.1, 2015.

Lorenz, E.: Climate predictability: The physical basis of climate modeling, GARP Publication Series, Vol. 16, WMO, 132-136, 1975.

Lott, F., Denvil, S., Butchart, N., Cagnazzo, C., Giorgetta, M. A., Hardiman, S. C., Manzini, E., Krismer, T., Duvel, J.-P., Maury, P., Scinocca, J. F., Watanabe, S., and Yukimoto, S.: Kelvin and Rossby-gravity wave packets in the lower stratosphere of some high-top CMIP5 models, J. Geophys. Res.-Atmos., 119, 21562173, doi:10.1002/2013JD020797, 2014.
McTaggart-Cowan, R., Girard, C., Plante, A., and Desgagneì, M.: The utility of upper-boundary nesting in NWP, Mon. Weather Rev., 139, 2117-2144, 2011.

Manzini, E., Karpechko, A. Yu., Anstey, J., Baldwin, M. P., Black, R.X., Cagnazzo, C., Calvo, N., Charlton-Perez, A., Christiansen, B., Davini, P., Gerber, E., Giorgetta, M., Gray, L., Hardiman, S. C., Lee, Y.-Y., Marsh, D. R., McDaniel, B. A., Purich, A., Scaife, A. A., Shindell, D., Son, S.-W., Watanabe, S., and Zappa, G.: Northern winter climate change: Assessment of uncertainty in CMIP5 projections related to stratospheretroposphere coupling, J. Geophys. Res.-Atmos., 119, 79797998, doi:10.1002/2013JD021403, 2014.

Min, S.-K. and Son, S.-W.: Multi-model attribution of the Southern Hemisphere Hadley cell widening: major role of ozone depletion, J. Geophys. Res.-Atmos., 118, 3007-3015, 2013.

Ming, A., Hitchcock, P., and Haynes, P.: The Double Peak in Upwelling and Heating in the Tropical Lower Stratosphere, J. Atmos. Sci., 73, 1889-1901, doi:10.1175/JAS-D-15-0293.1, 2016.

O’Neill, B. C., Tebaldi, C., van Vuuren, D., Eyring, V., Friedlingstein, P., Hurtt, G., Knutti, R., Kriegler, E., Lamarque, J.-F., Lowe, J., Meehl, J., Moss, R., Riahi, K., and Sanderson, B. M.: The Scenario Model Intercomparison Project (ScenarioMIP) for CMIP6, Geosci. Model Dev. Discuss., doi:10.5194/gmd-201684, in review, 2016.

Palmer, T. N., Shutts, G. J., and Swinbank, R.: Alleviation of a systematic westerly bias in general circulation and numeri- cal weather prediction models through an orographic gravitywave drag parameterization, Q. J. Roy. Meteor. Soc., 112, 1001-1039, 1986.

Pawson, S., Kodera, K., Hamilton, K., Shepherd, T. G., Beagley, S. R., Boville, B. A., Farrara, J. D., Fairlie, T. D. A., Kitoh, A., Lahoz, W. A., Langematz, U., Manzini, E., Rind, D. H., Scaife, A. A., Shibata, K., Simon, P., Swinbank, R., Takacs, L., Wilson, R. J., Al-Saadi, J. A., Amodei, M., Chiba, M., Coy, L., de Grandpré, J., Eckman, R. S., Fiorino, M., Grose, W. L., Koide, H., Koshyk, J. N., Li, D., J. Lerner, J., Mahlman, J. D., McFarlane, N. A., Mechoso, C. R., Molod, A., O’Neill, A., Pierce, R. B., Randel, W. J., Rood, R. B., and Wu, F.: The GCM-Reality Intercomparison Project for SPARC (GRIPS): Scientific Issues and Initial Results, B. Am. Meteor. Soc., 81, 781-796, 2000.

Plumb, R. A.: Stratospheric transport, J. Meteor. Soc. Jpn., 80, 793 809, 2002.

Polichtchouk, I. and Shepherd, T. G.: Zonal-mean circulation response to reduced air-sea momentum roughness, Q. J. Roy. Meteor. Soc., doi:10.1002/qj.2850, online first, 2016.

Reichler, T., Kim, J., Manzini, E., and Kroeger, J.: A stratospheric connection to Atlantic climate variability, Nat. Geosci., 5, 783787, doi:10.1038/NGEO1586, 2012.

Roff, G., Thompson, D. W. J., and Hendon, H.: Does increasing model stratospheric resolution improve extendedrange forecast skill?, Geophys. Res. Lett., 38, L05809, doi:10.1029/2010GL046515, 2011.

Scaife, A. A., Spangehl, T., Fereday, D. R., Cubasch, U., Langematz, U., Akiyoshi, H., Bekki, S., Braesicke, P., Butchart, N., Chipperfield, M. P., Gettelman, A., Hardiman, S. C., Michou, M., Rozanov, E., and Shepherd, T. G.: Climate change projections and stratosphere- troposphere interaction, Clim. Dynam., 38, 2089, doi:10.1007/s00382-011-1080-7, 2012. 
Shaw, T. A. and Voigt, A.: Tug of war on summertime circulation between radiative forcing and sea surface warming, Nat. Geosci., 8, 560-566, doi:10.1038/ngeo2449, 2015.

Shaw, T. A., Perlwitz, J., and Weiner, O.: Troposphere-stratosphere coupling: Links to North Atlantic weather and climate, including their representation in CMIP5 models, J. Geophys. Res., 119, 5864-5880, doi:10.1002/2013JD021191, 2014.

Shepherd, T. G.: Atmospheric circulation as a source of uncertainty in climate change projections, Nat. Geosci., 7, 703-708, doi:10.1038/NGEO2253, 2014.

Sigmond, M. and Scinocca, J. F.: The Influence of the Basic State on the Northern Hemisphere Circulation Response to Climate Change, J. Climate, 23, 1434-1446, doi:10.1175/2009JCLI3167.1, 2010.

Sigmond, M., Scinocca, J. F., Kharin, V. V., and Shepherd, T. G.: Enhanced seasonal forecast skill following stratospheric sudden warmings, Nat. Geosci., 6, 98-102, doi:10.1038/NGEO1698, 2013.

Simpson, I. R. and Polvani, L. M.: Revisiting the relationship between jet position, forced response and annular mode variability in the southern mid-latitudes, Geophys. Res. Lett., 43, 28962903, 2016.

Solomon, S., Rosenlof, K. H., Portmann, R. W., Daniel, J. S., Davis, S. M., Sanford, T. J., and Plattner, G.-K.: Contributions of stratospheric water vapor to decadal changes in the rate of global warming, Science, 327, 1219-1223, 2010.

Son, S.-W., Polvani, L. M., Waugh, D. W., Akiyoshi, H., Garcia, R., Kinnison, D., Pawson, S., Rozanov, E., Shepherd, T. G., and Shibata, K.: The impact of stratospheric ozone recovery on the Southern Hemisphere westerly jet, Science, 320, 1486-1489, 2008.

Swart, N. C. and Fyfe, J. C.: Observed and simulated changes in the Southern Hemisphere surface westerly wind-stress, Geophys. Res. Lett., 39, L16711, doi:10.1029/2012GL052810, 2012.

Thompson, D. W. J., Solomon, S., Kushner, P. J., England, M. H., Grise, K. M., and Karoly, D. J.: Signatures of the Antarctic ozone hole in Southern Hemisphere surface climate change, Nat. Geosci., 4, 741-749, doi:10.1038/NGEO1296, 2011.

Trenberth, K. E., Berry, J. C., and Buja, L. E.: Vertical Interpolation and Truncation of Model-coordinate Data, NCAR Technical Note NCAR/TN-396+STR, doi:10.5065/D6HX19NH, 1993.

Vallis, G. K.: Atmospheric and Oceanic Fluid Dynamics, Cambridge University Press, 745 pp., 2006.

Vallis, G. K., Zurita-Gotor, P., Cairns, C., and Kidston, J.: Response of the large-scale structure of the atmosphere to global warming, Q. J. Roy. Meteor. Soc., 141, 1479-1501, doi:10.1002/qj.2456, 2015.
Waugh, D. W. and Hall, T. M.: Age of stratospheric air: Theory, observations, and models, Rev. Geophys., 40, 1010, doi:10.1029/2000RG000101, 2002.

Webb, M. J., Andrews, T., Bodas-Salcedo, A., Bony, S., Bretherton, C. S., Chadwick, R., Chepfer, H., Douville, H., Good, P., Kay, J. E., Klein, S. A., Marchand, R., Medeiros, B., Siebesma, A. P., Skinner, C. B., Stevens, B., Tselioudis, G., Tsushima, Y., and Watanabe, M.: The Cloud Feedback Model Intercomparison Project (CFMIP) contribution to CMIP6, Geosci. Model Dev. Discuss., doi:10.5194/gmd-2016-70, in review, 2016.

Wenzel, S., Eyring, V., Gerber, E. P., and Karpechko, A. Yu.: Constraining Future Austral Jet Stream Position and Shifts in the CMIP5 Ensemble by Process-oriented Multiple Diagnostic Regression, J. Climate, 29, 673-687, doi:10.1175/JCLI-D-150412.1, 2016.

Wilcox, L. and Charlton-Perez, A: Final warming of the Southern Hemisphere polar vortex in high- and low-top CMIP5 models. J. Geophys. Res.-Atmos., 118, 2535-2546, doi:10.1002/jgrd.50254, 2013.

Wright, J. S. and Fueglistaler, S.: Large differences in reanalyses of diabatic heating in the tropical upper troposphere and lower stratosphere, Atmos. Chem. Phys., 13, 9565-9576, doi:10.5194/acp-13-9565-2013, 2013.

Wu, Y., Seager, R., Shaw, T. A., Ting, M., and Naik, N.: Atmospheric circulation response to an instantaneous doubling of carbon dioxide. Part II: Atmospheric transient adjustment and its dynamics, J. Climate, 26, 918-935, 2013.

Yoo, C. and Son, S.-W.: Modulation of the boreal wintertime Madden-Julian Oscillation by the stratospheric QuasiBiennial Oscillation, Geophys. Res. Lett., 43, 1392-1398, doi:10.1002/2016gl067762, 2016.

Zanchettin, D., Khodri, M., Timmreck, C., Toohey, M., Schmidt, A., Gerber, E. P., Hegerl, G., Robock, A., Pausata, F. S. R., Ball, W. T., Bauer, S. E., Bekki, S., Dhomse, S. S., LeGrande, A. N., Mann, G. W., Marshall, L., Mills, M., Marchand, M., Niemeier, U., Poulain, V., Rozanov, E., Rubino, A., Stenke, A., Tsigaridis, K., and Tummon, F.: The Model Intercomparison Project on the climatic response to Volcanic forcing (VolMIP): experimental design and forcing input data for CMIP6, Geosci. Model Dev., 9, 2701-2719, doi:10.5194/gmd-9-2701-2016, 2016. 